21(4): 529-41

14. Rutter M. Autism as a Genetic Disorder. In: McGuffin P, Murray R, eds. Mental illness and the new genetics. Oxford; Heinemann Medical, 1991.

15. Szatmari $P$. The validity of autistic spectrum disorders: a literature review. J Autism Develop Dis 1992, 22(4): 583-600.

\section{Mania and mobile phones}

Sir - The modes of presentation of mental illness are clearly influenced by contemporary social circumstances; best illustrated by the decline in prevalence of religious delusions over the last century.1 New technologies have been reported to alter phenomenological content, 2 and this current report shows an area of behaviour increasingly problematic in hypomania due to technological change. Admission to hospital for the mentally ill is seen in large part as protective for the sufferer against their actions. The following cases illustrate a behaviour pattern occurring in hypomania, where admission to hospital is not necessarily protective.

A 48 year old, separated photographer, with a past history of manic depressive psychosis, was admitted compulsorily following concern expressed by his friends since he had hired a helicopter to take his daughter to Euro Disney. He had spent over $£ 16,000$ in the two days prior to his admission. His mental state revealed a gentleman with flamboyant dress, over familiarity, pressure of speech and numerous grandiose and expansive delusions. During his stay on the ward he persisted with ideas of being a major international businessman, and to this end insisted on using a mobile phone whilst detained. He was able to communicate with various financial offices during his stay, much to the annoyance of those receiving the calls, and made various contractual arrangements. He absconded from the ward 24 days after his admission. His mental state was largely unchanged.

A 34 year old with a past history of manic depressive psychosis was admitted voluntarily following increasing agitation, insomnia, and the expression of bizarre paranoid ideas. His girifriend reported him using his mobile phone with increasing regularity.

Mental state on admission was consistent with hypomania. During his stay on the ward he continued to use his mobile phone until the battery expired. At the suggestion of ward staff his girlfriend did not bring in the recharger. He made an uneventful recovery and has returned to work taking lithium prophylaxis.

A 30 year old, single, computer operator was admitted compulsorily in an agitated, grandiose state having recently been treated for a depressive episode with fluoxetine $20 \mathrm{mgs}$ a day. He believed himself to be of immense importance and to be essential for the safe running of a major bank's computer system who would lose $£ 182,000$ a second during his admission. He was concerned that the bank would not be able to contact him and so had purchased mobile phones and radio-pagers to ensure contact could be made. He insisted on using such devices during his stay making repeated calls to his family in New Zealand. He refused to allow staff to care for the equipment who therefore allowed the batteries to run down to prevent further use. He made an uneventful recovery. Afterwards he was faced with bills for $£ 4,500$ for the equipment and calls.

The ill-judged behaviour of hypomanic patients with regard to financial arrangements is well known. Admission to hospital normally prevents further ill-conceived arrangements being made. The widespread use of mobile phones is a relatively new phenomenon and is becoming increasingly common in London. In all three cases they had clearly been a problem preceding the admissions and in cases $\mathrm{A}$ and $\mathrm{C}$ remained problematic during the patient's stay. Neither patient was prepared to voluntarily hand over their devices and the least confrontational method of reducing their use, and the consequences thereof, was to allow the batteries to expire. Restricting patients freedom is never undertaken likely; a detained patient may be allowed their keys providing the unit is secure, but it is impossible to make a unit 'secure' with respect to mobile phone usage. Considerable thought was given before limiting access to communication, but the teams eventually considered it necessary to limit use. Whilst the Code Of Practice ${ }^{3}$ states that patients should not be deprived of "aids necessary for their daily living", limitation of the irresponsible use of mobile phones appeared to be the only sensible way to prevent serious consequences for these patients from their mental illness.

Andrew Smith, MBBS, DCH, MRCPsych Registrar in Psychiatry, South Kensington \& Chelsea Mental Health Centre, 1 Nightingale Place, London, SWIO 9NG, England.

References

1. Klaf \& Hamilton. Schizophrenia: a hundred years ago and today. J Ment Sci 1961; 1 07: 819-27.

2. Spence SA: Nintendo hallucinations: a new phenomenological entity. Ir J Psych Med 1993; 10(2): 98-9.

3. Code Of Practice: Mental Health Act 1983. HMSO.

\section{Bilateral foot-drop and electroconvulsive therapy}

Sir - We report a case of bilateral foot-drop due to common peroneal nerve palsies which became obvious immediately at the end of a course of electroconvulsive therapy and discuss the possible aetiologies. To our knowledge this is the first such report.

$\mathrm{Z}$, a 67 year old male was admitted to hospital with psychotic depression following a failed trial of lofepramine. He believed that he had blocked, odoriferous bowels and bladder, and was worried lest he might have cancer and AIDs which people could catch from a toilet seat he had used. He gave up food and drink in an attempt to relieve the blockage and spent days digging for a 'broken pipe' in a rain -flooded field despite assurance that one did not exist. The illness appears to have started a few months before admission. $Z$ had received uneventful ECT for psychotic depression when he was aged 29 years and remained well until the index episode. When well, he was of a quiet, anxious disposition. He retired from his warehouse job nine years previously. He never drank alcohol and had not smoked in years.

On admission, $Z$ was agitated, mumbling, pessimistic, depressed, wringing his hands and afraid lest the examiner would catch his disease. He was "finished" and believed we would "put him down". He was fully orientated, had no suicidal thoughts, and denied auditory hallucinations. He was treated with thioridazine $100 \mathrm{mgs}$ QID and trazodone 50mgs BID and $100 \mathrm{mgs}$ nocte (later $150 \mathrm{mgs}$ nocte). Physical examination revealed widespread expiratory rhonchi, an intact nervous system, and a normal prostate and ECG. He consented to ECT but was not hopeful about the outcome.

He received seven uneventful bilateral treatments ( $3 /$ week; average clinical fit duration $=11.8$ secs, range $10-15$ secs; average stimulus $=282 \mathrm{mC}$, range $=250-325 \mathrm{mC}$ ) leading to restoration of a completely normal mental state. He remained fully orientated throughout. Thioridazine had been reduced to $25 \mathrm{mgs}$ nocte by the time of the seventh treatment.

At the end of the course of ECT, $\mathrm{Z}$ was noted to be walking by raising both heels off the ground. All of his reflexes were brisk and equal on both sides. His plantars were down-going, but he had weakness of dorsiflexion of both feet, this being more marked on the left side. B12, folate, FBC, TPHA, VDRL, SMAC, acid phosphatase, chest-Xray, blood glucose and EEG were normal. He had mild degenerative changes in his lumbar spine. Physiotherapy and walking were prescribed and he was discharged on trazodone only.

One week later he was readmitted with a return of his original psychotic symptoms, together with the delusional belief that his penis was diseased. His gait was unchanged. There was no priapism. Trazodone was stopped, although no report of foot-drop could be found to incriminate it. This time he was treated with thioridazine 50mgs QID and trifluoperazine 5mgs QID. Because of 
only minimal improvements, setraline 50mgs BID was commenced two weeks after admission. At this stage he was seen at the neurological clinic and a diagnosis of bilateral external popliteal (common peroneal) nerve compression at the neck of the fibulae was confirmed by electromyography. The prognosis was considered to be good, and foot drop splints were prescribed. Fifty-six days after admission $\mathrm{Z}$ was discharged on sertraline $100 \mathrm{mgs}$ BID, thioridazine $25 \mathrm{mgs}$ BID, $50 \mathrm{mgs}$ nocte, and trifluoperazine $3 \mathrm{mgs}$ BID and 3mgs nocte. An appointment for a CT scan arrived after he had gone home and it was decided not to avail of it.

At five months follow-up Z's mental state was normal, he was taking his medication and wearing splints some of the time, and was optimistic in outlook. There were no new neurological signs and his ability to dorsiflex his ankles was significantly improved.

Cases of unilateral peroneal nerve palsy have been described in patients receiving ECT, ${ }^{\prime}$ but ours is the first description of ECT and bilateral foot-drop. All the unilateral cases improved in from weeks to months and the authors were unable to find convincing reasons for injury to this vulnerable nerve. ${ }^{2}$ Habitual crosssing of the legs, ${ }^{3}$ spring clipgs, ${ }^{4}$ gross osteoarthritis of the knees, dashboard injury, ${ }^{5}$ diabetes mellitus, chronic renal failure, peripheral neuropathy, severe weight loss, tight Plaster of Paris, recent prolonged immobility in bed, various other taumata such as direct blows, lacerations, fractures of the neck of fibula, various injuries to the knee joint, and posterior disolocation of the superior tibio-fibular joint, ${ }^{6}$ as well as ganglia, osteomata, and exostoses have been implicated.' A few cases may fail to recover.

We found no evidence to suggest unusual force being exerted on our patients' knees (neurapraxia) during ECT. There was no evidence of ischaemia of the lower limbs or of a metabolic disorder. General anaesthesia and succylcholine are most unlikely to be causally related (Cunningham AJ, personal communication). A point against leg-crossing as a cause in the index case is the fact that all of the Nagler and Rangell ${ }^{3}$ cases were unilateral.

We cannot rule out a drug-related neuropathic disorder in this case. However, apart from very rare references to peripheral neuropathy associated with tricyclic anti-depressants, ${ }^{9}$ it is difficult to incriminate (but equally impossible to rule out) a chemotherapeutic aetiology.,10 Our cases may well be related to ECT itself (simple being bilateral instead of unilateral), pressure exerted during ECT, bed rest, poor nurishment and/or sedatio. Like an earlier author, ${ }^{1}$ we have no definite aetiological explanation.

Brian O'Shea, FRCPsych, Consultant Psychiatrist, Mary O'Brien, MB, Psychiatry Senior House Officer, Newcastle Hospital, Co Wicklow,

Niall Tubridy, MRCPI, Neurology Registrar, Michael Hutchinson, FRCPI, Consultant Neurologist, St. Vincent's Hospital, Dublin 4, Ireland.

References

1. Mason E. Peroneal nerve palsy seen in patients treated with electroconvulsive therapy. AM J Psychiatry 1955; 112: 299-300.

2. Garland $H$, Moorhouse D. Compressive lesions of the external popliteal (common peronea) nerve. BMJ 1952; ii: 1373-8.

3. Nagler SH, Rangell L. Peroneal palsy caused by crossing the legs. JAMA 1947; 133: $755-61$.

4. Denny-Brown D, Brenner C. Lesion in peripheral nerve resulting from compression by spring clip. Arch Neurol Psychiatry 1944; 52: 1-19.

5 . Sidey JD. Weak ankles: a study of common peroneal entrapment neuropathy. BMJ 1969; ii: 623-6.

6. Katirji MB, Wilbourn AJ. Common peroneal mononeuropathy: a clinical and electrophysiologic study of 116 lesions. Neurology 1988; 38: 1723-8.

7. O'Brien DF, Kaar TK, McGuinness AJ. Intraneural ganglion of the peroneal nerve: a case report. IMJ 195; 88: 131.

8. O'Shea B, Falvey J. A textbook of psychological medicine (3rd ed). Dublin: EHB Press, 1993.

9. Silverstone T, Turner P. Drug treatment in psychiatry (5th ed). London: Routledge, 1995.

10. Cookson J, Cranmer J, Heine B. The use of drugs in psychiatry (4th ed). London: Gaskell, 1993.

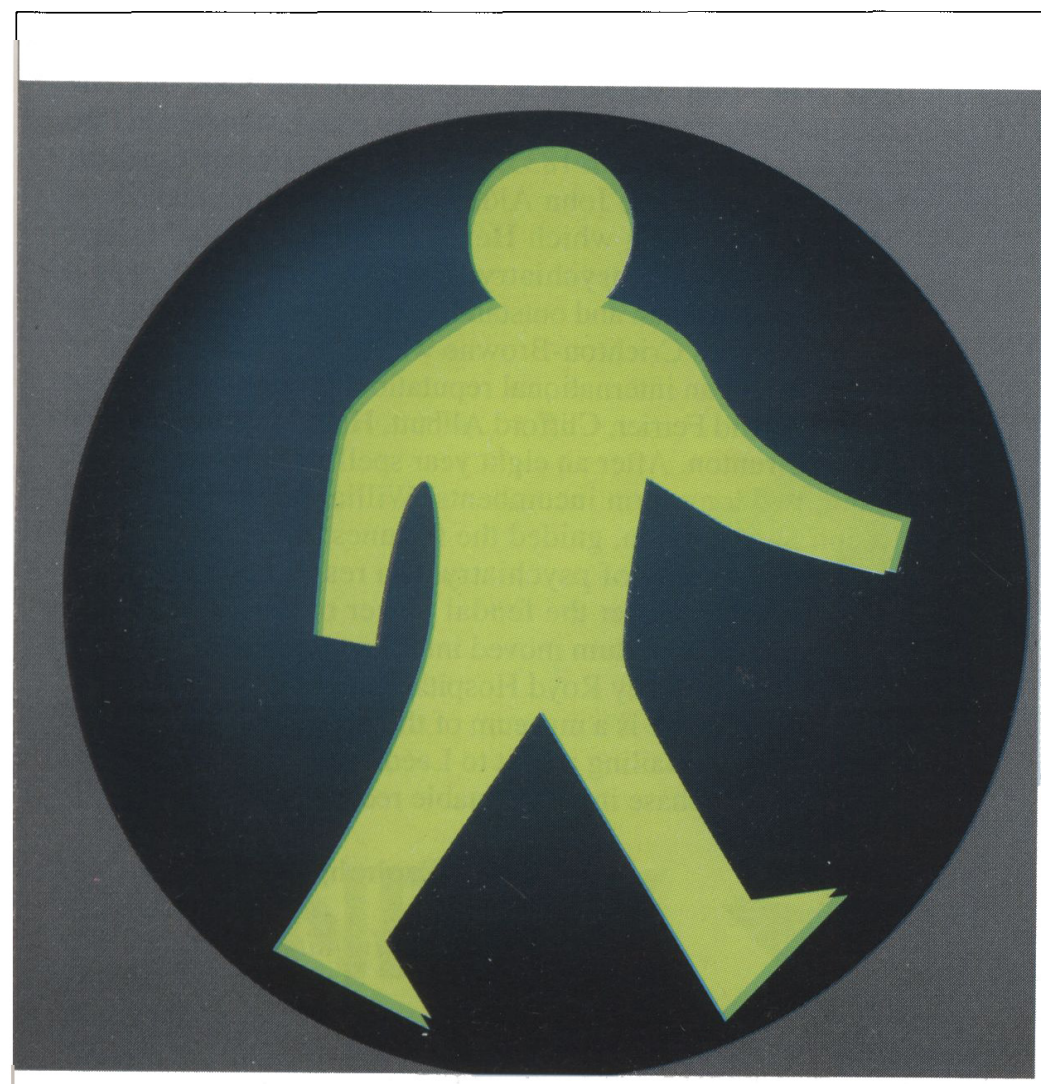

